\title{
Erratum
}

\section{Dynamic Fluctuations in Optical Bistability}

\author{
M. DelleDonne, P.H. Richter, and J. Ross \\ Department of Chemistry, Stanford University, Stanford, California, USA
}

We thank Dr. Hänggi for pointing out ref. [1] in which the same results were obtained as in Sect. VI of our paper, although with different parameter choices, and with different interpretation. We regret that this article had escaped our attention.

\section{Reference}

1. Hänggi, P., Bulsara, A.R., Janda, R.: Phys. Rev. A 22, 671 (1980)
M. DelleDonne

Department of Chemistry

Stanford University

Stanford, CA 94305

USA

P.H. Richter

Fachbereich Physik

Universität Bremen

D-2800 Bremen 33

Federal Republic of Germany 